\title{
Designing Smart Supplier Chain Management Model under Big Data and Internet of Things Environment
}

\begin{abstract}
Recently, the business paradigm has shifted to the direction of strengthening consumer-oriented process interconnections and thus demand diversity and volatility have increased. The automation, autonomy, and connectivity of the entire supply chain are emphasized on the basis of the fourth industry technology such as Internet of things and artificial intelligence. In this paper, we propose a smart Supply Chain Management model that accommodates current high technological issues and business requirements under 4th industrial revolution era. The proposed web based SCM consists of automatic ordering/purchasing system, artificial intelligence based appropriate inventory computation system based on Monte Carlo simulation, and detachable IoT based inventory management system. The system is expected to be a sophisticated and intelligent smart SCM solution that adheres to logistics standards for visibility, safety and efficiency.
\end{abstract}

Am-suk Oh
Keywords : SCM, Big Data, Internet of Things, Automatic Ordering / Purchasing System, Automatic Inventory Management

\section{INTRODUCTION}

$\mathrm{F}_{\text {irst introduced by Oliver and Webber [1], supply chain }}$ management (SCM) aims at improving the allocation, management and control of logistical resources by identifying and integrating the resources and procedures of different sectors in a supply chain. A supply chain is a network of facilities and distribution options that performs the functions of material procurement, transformation of these materials into intermediate and finished products, and distribution of these finished products to customers [2].

If properly designed, a series of decision supporting systems that share production and inventory information among business partners in the supply chain enjoy mutual benefits of cost reduction and efficient product cycle management such as improved coordination of logistics activities and improved shipment [3,4]. However, supply chain collaboration may fail due to unsuccessful information exchange due to inefficient management of confidential information of different partners or inappropriate responses to the rapid changes of high product variety and customization at on-time delivery and material shortage uncertainties [5]. One of popular problems in SCM is the bullwhip effect refers to the phenomenon where order variability increases as the orders move upstream in the supply chain [6].

Revised Manuscript Received on July 22, 2019

* Correspondence Author

Am-suk Oh*, Department of Digital Media Engineering, Tongmyong University/Busan, Korea. Email: asoh@tu.ac.kr

These uncertainties result from poor management of information from suppliers, manufacturers, and customers. Thus sustainable SCM systems are studied and applied to many different manufacturing fields in last decade $[7,8]$. To make it worse, business partners within global supply chains generates huge amounts of raw-data. Thus, current web-based SCM $[9,10]$ should be further developed to fit such environmental changes - big data and IoT era.

The Internet of things (IoT) is a next generation of Internet connected embedded ICT systems in a digital environment to seamlessly integrate supply chain and logistics processes.

Integrating emerging IoT into the current ICT systems can be unique because of its intelligence, autonomous and pervasive applications [11]. IoT bridges the gap between physical and digital world by synchronizing the information flow with the physical flow for greater supply chain integration. Several systems are proposed and reviewed to utilize most recent sensor technology under SCM framework .

Big data refers to the current and future information processing environment in the computerized world. It not only refers to the large volume which has exponentially increased, also includes the variety of data generated from heterogeneous sources such as IoT sensors, mobile devices, online social networks, etc., in structured, semi-structured, and unstructured formats. The speed of data generation and delivery, the importance of data quality and level of trust, the process of revealing underexploited values from Big data to support decision-making are also common characteristics of big data affecting computerized business systems.

Most recently, the concept of "Smart City" is drawn to the computing world. A smart city refers to a city seeking to address public issues via information and communication technology- based solutions on the basis of a multi- stakeholder, municipally based partnership. It encompasses an extremely diversified set of public initiatives: from building better transportation systems to supporting creative innovation, or designing energy- saving policies. The IBM's CEO, Sam Palmisano, characterized the smart city with 3i World - instrumented, interconnected and intelligent covering whatever you like to be more efficient, sustainable, and intelligent. However, the adoption of smart city concepts poses both opportunities and constraints to supply chain management. It can provide open data systems based on diversified sources (e.g. public data, citizen- produced content or urban sensors). This can be particularly critical in the mobility aspects of the supply 
chain. The SCM applications of big data can be utilized in all the key processes of SCM. However, incomplete systems using such diverse information sources may lead the information system to draw wrong conclusion that is hard to refute or being explained.

In this paper, we propose a design of smart SCM model that can accommodate most requirement of small/medium level business enterprises in the supply chain. The proposed web based SCM consists of automatic ordering/purchasing system, artificial intelligence based appropriate inventory computation system, and detachable IoT based inventory management system. This SCM model stresses the autonomy, interconnected automation of business processes based on big data treatment and IoT generated information utilization in SCM cycle.

\section{SMART SCM REQUIREMENT}

Smart SCM aims at maximizing the corporate profits through efficient inventory management and timely supply of products, and solves the complex management problems caused by a wide range of markets. It connects various business partners that have dealings with suppliers, producers and customers. Under $3 i$ world concept as the key elements of smart SCM, the requirements of the SCM can be summarized as shown in Table-I.

Table-I: Key Elements and Requirements of Smart SCM

\begin{tabular}{|c|l|}
\hline Key Elements & \multicolumn{1}{c|}{ Requirements } \\
\hline Instrumented & $\begin{array}{l}\text { - Converted to the way that containers, } \\
\text { trucks, products, and production facilities } \\
\text { themselves report information for people, } \\
\text { instead of a manual monitoring process. }\end{array}$ \\
\hline Interconnected & $\begin{array}{l}\text { - Contains all objects that are monitored in } \\
\text { the supply chain as well as traditional } \\
\text { connections such as customers, partners, } \\
\text { and IT systems }\end{array}$ \\
\hline Intelligent & $\begin{array}{l}\text { - Smart SCM should be able to provide a } \\
\text { solution to global optimization based on } \\
\text { artificial intelligence. }\end{array}$ \\
\hline
\end{tabular}

In Korea, it is analyzed that the domestic manufacturing industry considers supply chain resource operation function of inventory management, basic information management, sales management, and monitoring as a key utilization strategy to improve the information visibility and operational efficiency. However, transportation planning, manufacturing planning, and logistics planning are relatively less utilized in the real world. A recent research from the government agency reports the desirable requirements of smart SCM as following.

1) Technology for establishing safe and efficient logistics flow by collecting, linking, processing, and providing related information such as location, status, and security of products occurring in logistics activities

2) Technology for real-time information monitoring and acquisition of equipment, facilities, products, etc.

3) Technology for linking information between logistics related equipment, facilities, products and operating systems
4) Visualization of SCM logistics information to support efficient logistics decision making

5) Technology for preemptive countermeasures against logistics security-related systems that are strengthening internationally and the possibility of non-tariff trade barriers is increasing.

6) Security system and electronic seal technology (e-Seal) for logistic flow products and unit loads.

Based on the above theoretical assessment and practical industry consulting experiences for many manufacturing companies, we summarize the most important elements of proposed SCM model as shown in Table-II.

Table- II: Difficulties and Proposed Solutions in Smart SCM

\begin{tabular}{|c|c|c|}
\hline Elements & Difficulty & Solution \\
\hline $\begin{array}{l}\text { Purchasing/Ordering } \\
\text { Management }\end{array}$ & Using ERP & $\begin{array}{l}\text { Real time } \\
\text { information } \\
\text { sharing based on } \\
\text { AI algorithm to } \\
\text { reduce the error. }\end{array}$ \\
\hline $\begin{array}{l}\text { Inbound/Outbound } \\
\text { Management }\end{array}$ & $\begin{array}{l}\text { Using } \\
\text { ERP/Manual }\end{array}$ & $\begin{array}{l}\text { Real time } \\
\text { Management by } \\
\text { IoT sensor } \\
\text { information. }\end{array}$ \\
\hline Current Inventory & $\begin{array}{l}\text { Inaccurate due } \\
\text { to manual } \\
\text { process } \\
\text { involved. }\end{array}$ & $\begin{array}{l}\text { Real time } \\
\text { Management by } \\
\text { IoT sensor } \\
\text { information. }\end{array}$ \\
\hline Traceability & $\begin{array}{l}\text { Limited } \\
\text { information on } \\
\text { Lot and } \\
\text { History } \\
\text { Management }\end{array}$ & $\begin{array}{l}\text { Real time } \\
\text { Management by } \\
\text { IoT sensor } \\
\text { information. }\end{array}$ \\
\hline FIFO & Inefficient & $\begin{array}{l}\text { Systematic FIFO } \\
\text { Management }\end{array}$ \\
\hline Daily Work Close & $\begin{array}{l}\text { Human } \\
\text { intervention } \\
\text { required. }\end{array}$ & $\begin{array}{l}\text { Real time } \\
\text { information } \\
\text { sharing }\end{array}$ \\
\hline Partner Evaluation & $\begin{array}{l}\text { Subjective/Not } \\
\text { enough } \\
\text { information }\end{array}$ & $\begin{array}{l}\text { Big Data } \\
\text { Analysis based } \\
\text { on UIT } \\
\text { information. }\end{array}$ \\
\hline
\end{tabular}

\section{PROPOSED SYSTEM MODEL}

\section{A. Overall Architecture}

The proposed model consists of three subsystems. The architecture of the proposed SCM is as shown in figure 1 and the role of each subsystem is as following;

1) Automatic Purchasing/Ordering System : Web-based system for real-time sharing of product data such as production planning information, ordering information, delivery information, quality determination information, and stock status with suppliers.

2) Automatic Computation of

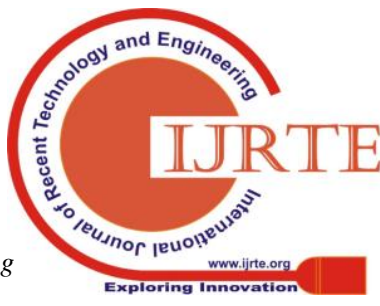


Appropriate Safe Inventory: AI based safe inventory computation algorithm based on inventory shortage pattern analysis.

3) Automatic Inventory Management System: IoT based Inbound/Outbound Management.

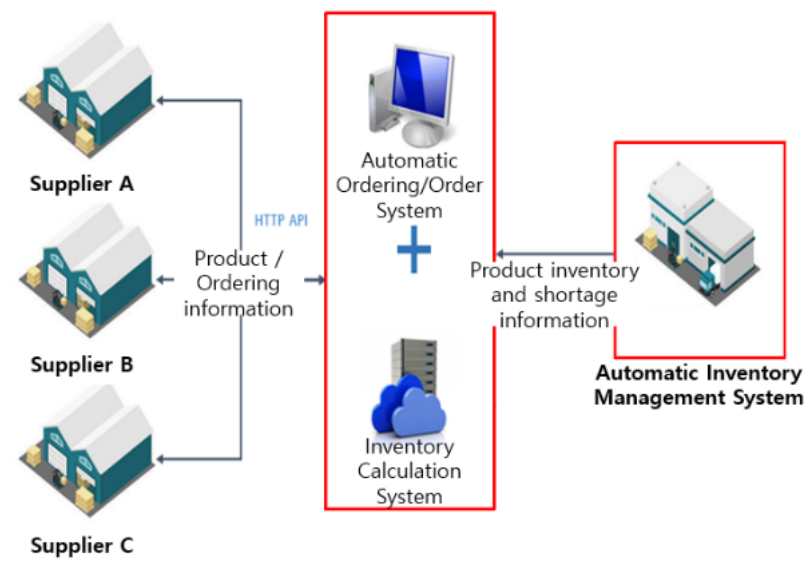

Fig. 1. Smart SCM Solution Architecture

\section{B. Web based Purchasing/Ordering System}

The automated Purchasing / Ordering system is a web-based system that shares product data such as production planning information, ordering information, delivery information, quality determination information, and inventory status in real time among business partners in the supply chain. The information sharing architecture is organized as shown in Figure 2.
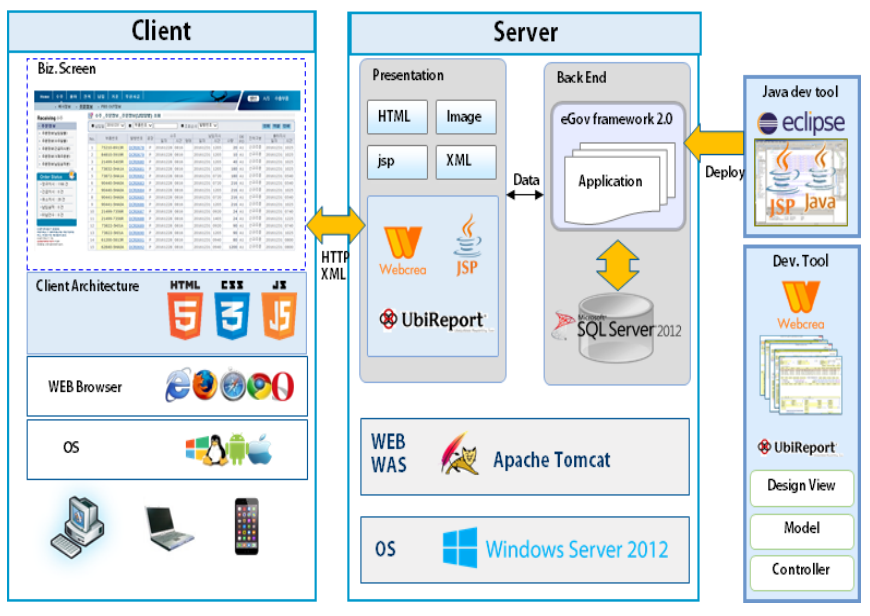

Fig. 2. MSSQL based Server for Information Sharing

Details of Purchasing/Ordering Process are as following;

1) When a customer's order is entered, the intelligent ordering system based on the reference information in the ordering module of system treats the order based on the standard as the registered producing partner. The shipment module issues the delivery note to the desired delivery order. In the delivery module, the goods receipt and shipment waiting service are performed. In the quality module, defects are checked through the inspection of the received parts and the returning product is registered if exists. Such defect information will be used to evaluate the partner companies in the future. In the customer shipment module, the information delivered to the customer is registered and the order is completed. The basic module manages the basic information of the partner companies, parts for ordering, due date for ordering and safety stock quantity.

2) The basic information required by the web ordering system is synchronized with the ERP, and it is automatically back-ended with the customer's system to receive the order information and support the automatic ordering.

The detailed technological issues with respect to the operational activity are summarized in Table-III

Table-III: Activity-Technology Details

\begin{tabular}{|c|c|}
\hline Activity & Technology \\
\hline Ordering & $\begin{array}{l}\text { (1) Direct Input } \\
\text { (2) File Upload } \\
\text { (3) FTP interface } \\
\text { (4) API } \\
\text { (5) Database Link }\end{array}$ \\
\hline Purchasing & $\begin{array}{l}\text { - AI based computation } \\
\text { - Safe Stock Management } \\
\text { - Safe Shipment Planning } \\
\text { - Lead Time etc. }\end{array}$ \\
\hline Shipment & $\begin{array}{l}\text { (1) Issuing Barcode labels } \\
\text { (2) IOT device-Purchasing } \\
\text { registration }\end{array}$ \\
\hline Inbound & $\begin{array}{l}\text { (1) Scanning Labels } \\
\text { (2) Scanning information from } \\
\text { IOT/mobile devices }\end{array}$ \\
\hline Quality Control & - Partner performance evaluation \\
\hline Outbound & - Database Control \\
\hline Basic & $\begin{array}{l}\text { - IOT device registration } \\
\text { - Part/Supplying Partner } \\
\text { registration }\end{array}$ \\
\hline
\end{tabular}

The proposed model has a platform architecture as shown in Figure 3 and details of the related modules are explained in Table-IV. 


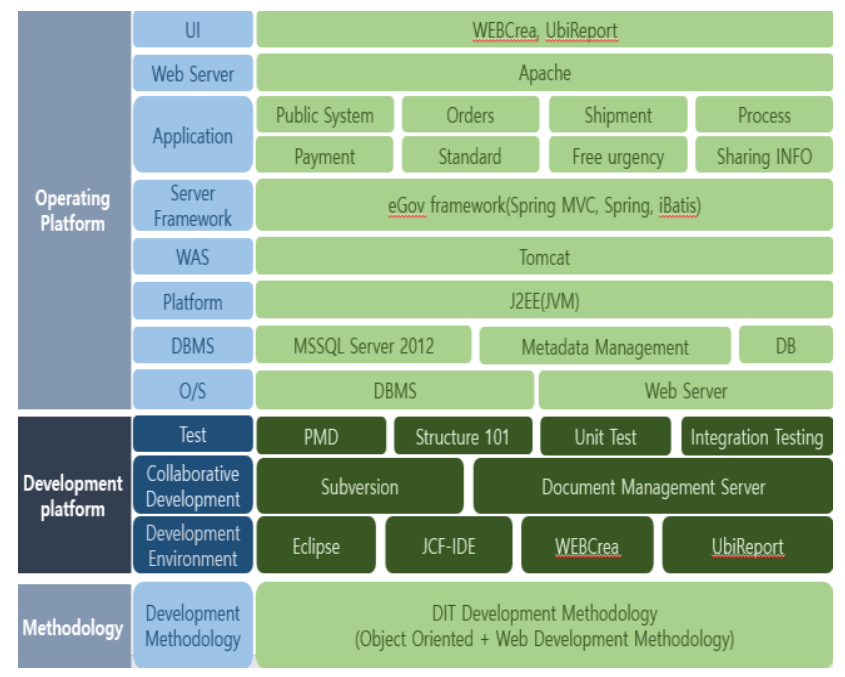

Fig. 3. Purchasing/Ordering System and Platforms

Table-IV: Platforms and Technical Contents

\begin{tabular}{|l|l|}
\hline Platform & Contents \\
\hline $\begin{array}{l}\text { Management } \\
\text { Platform }\end{array}$ & $\begin{array}{l}\text { - HTML5 based } \\
\text { Server(+Oracle) }\end{array}$ \\
\hline $\begin{array}{l}\text { Development } \\
\text { Platform }\end{array}$ & $\begin{array}{l}\text { - System for Development and Test } \\
\text { Platform } \\
\text { - Unit/Module/Integration Test }\end{array}$ \\
\hline Strategy & $\begin{array}{l}\text { - Object-Oriented } \\
\bullet \text { Web-based }\end{array}$ \\
\hline
\end{tabular}

With such technical contents, the proposed smart SCM provides intelligent purchasing/ordering management system.

\section{Automatic Inventory Management System}

In automatic inventory management, we need to obtain information from various sources including IoT devices. We propose a detachable IoT device based system that is able to trace the product history from ordering to outbound process. The configuration of proposed detachable IoT devices is shown as Figure 4. IoT devices have embedded Hall sensors and they are detachable tag forms thus their attach/detach status are automatically recognizable. When they are attached, they transfer registered product information automatically and such information is automatically reset when they are detached. Logistics information of the product such as damage during moving, loss during storage, etc. are recorded by using acceleration sensors. Information collected through such tags is transmitted to the server through the inventory management system. Bluetooth Low Energy (BLE) technology is used in this data network management. Inventory management status can be monitored by mobile devices as well. Figure 4 demonstrates the configuration of IoT devices and data transmission architecture.

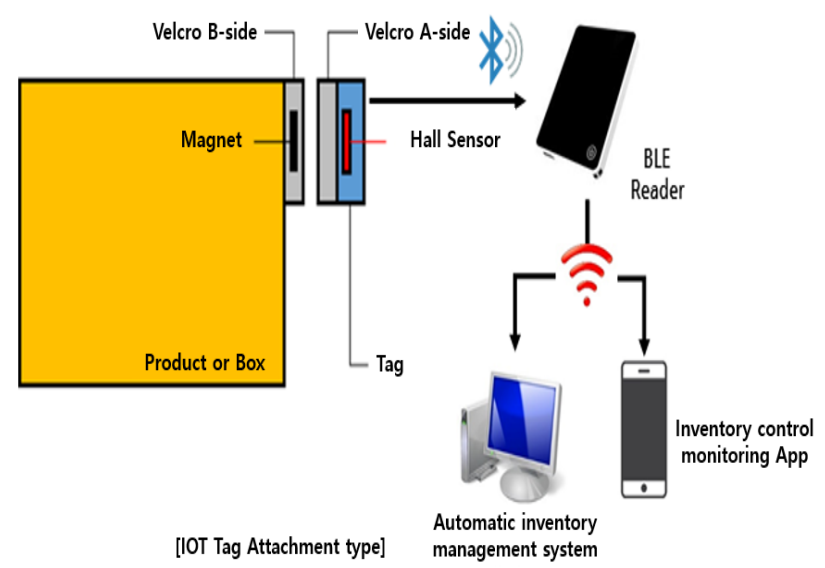

Fig. 4. Detachable IoT device Configuration

In order to maintain efficient inventory management, the system needs to compute the amount of safe stock for each product/material. Based on artificial intelligence technology, we derive the appropriate inventory level and predict the order quantity and reorder point that minimizes the total inventory cost based on the field information obtained in order to manage the variation of demand and lead time variation affecting inventory. Accumulate information on the supplier-specific shortages and derive safety inventory of the products through statistical analysis. Collected data from various sources including unformatted data are translated to the computable forms by big data analysis tools.

Them, we apply Monte Carlo simulation to estimate the safe stock amount of the parts/products. Monte Carlo simulation is a technique for finding statistical information about a value resulting from calculations performed on a set of random variables. For a large number of trials, the frequency distribution of the calculated results should approximate the true probability distribution of the value of interest. This technique has been used in SCM risk management and stochastic inventory demand computation with heuristics.

\section{CONCLUSION}

In this paper, a smart SCM model between a manufacturer and a supplier is presented based on the fourth industrial revolution technology such as artificial intelligence and the IoT sensor technology. The proposed model consists of automatic ordering/purchasing system, artificial intelligence based appropriate inventory computation system, and detachable IoT based inventory management system. This SCM model stresses the autonomy, interconnected automation of business processes based on big data treatment and IoT generated information utilization in SCM cycle. The system complies with logistics standards for visibility, safety and efficiency. This smart SCM solution aims at maximizing corporate profits through efficient inventory management and timely supply of products, and solves the complex management problems caused by a wide range of markets.

The potential benefits of the proposed smart SCM model are as following; 
1) Strengthening business partner services;

- Share ordering / delivery information through online service

Flexibility in supplier production planning through sharing of example and discontinuation information

- Real-time payment status and advance payment confirmation

Real-time payment performance by company

2) Improve productivity of purchasing / logistics services;

Real-time history management and traceability

- Strengthen the purchasing / logistics management capacity of practitioners

Reduction of lead time / cycle time such as receipt and finishing results

3) System based real time monitoring

Real-time progress management from order to delivery

Rapid decision support for emergency situations

Company evaluation and management based on accurate data

4) Cost reduction by process improvement

- Appropriates inventory management by order type subdivision (inventory reduction)

Ensuring reliability of inventory accuracy and inventory control

Improved delivery quality and cost reduction by improving the production / delivery process of suppliers

\section{ACKNOWLEDGMENT}

This work was supported by the BB21+ Project in 2018 . This research was supported by the Tongmyong University Research Grants 2019(2019F010).

\section{REFERENCES}

1. R. K. Oliver, M. D. Webber, "Supply-chain management: logistics catches up with strategy," Outlook, 1982

2. R. Ganeshan, T. P. Harrison, "An introduction to supply chain management, in Supply Chain Management, Version 1." Available: http://silmaril.smeal.psu.edu/misc/supply_chain_intro.html.

3. G. Dellino, T. Laudadio, R. Mari, N. Masronardi and C. Meloni, "A reliable decision support system for fresh food supply chain management", International Journal of Production Research, Feb. 2018, PP. 1458-1485.

4. P. M. Reyes, W. J. Worthington and J. D. Collins, "Knowledge management enterprise and RFID systems: Adoption to supply chain performance," Management Research Review, Jan. 2015, pp. 44-66.

5. Chang, Y. Ping, "A Wep-Based System for Supply Chain Collaboration to Enhance Agility and Flexibility." In Handbook of Research on the Evolution of IT and the Rise of E_Society, IGI Global, 2019, pp. 108-123.

6. X. Wang, S. M. Disney, "The bullwhip effect: Progress, trends and directions." European Journal of Operational Research, May 2016, pp. 691-701.

7. P. Taticch, P. Garengo, S. S. Nudurupati, F. Tonelli and R. Pasqualino, "A review of decision-support tools and performance measurement and sustainable supply chain management." International Journal of Production Research, Nov. 2015, pp. 6473-6494.

8. A. Touboulic and H. Walker, "Theories in sustainable supply chain management: a structured literature review." International Journal of Physical Distribution \& Logistics Management, Mar. 2015, pp. 16-42.

9. C. Danila, G. Stegaru, A. M. Stanescu and C. Serbanescu, "Web-service based architecture to support SCM context-awareness and interoperability." Journal of Intelligent Manufacturing, Feb. 2016, pp. 73-82.
10. P. Kamalendu., "Supply Chain Coordination Based on Web Service." In Supply Chain Management in the Big Data Era, IGI Global, 2017, pp. 137-170.

11. T. de Vass, H. Shee and S. J. Miah, "The effect of 'Internet of Things' on supply chain integration and performance: An organisational capability perspective." Australasian Journal of Information Systems, Jun. 2018, pp. 22-31.

\section{AUTHORS PROFILE}

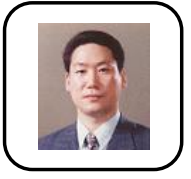

Am-suk Oh* received the B.S. and M.S. degrees in computer science from Busan National University and Chung-ang University, respectively. He received $\mathrm{Ph} . \mathrm{D}$ degree at the computer engineering of Busan National University. He is currently with the Department of Digital Media Engineering, Tongmyong University as Professor. His research interests are Database, Healthcare System, Big Data and IoT. 